\title{
Uma história de outros regressos: a comunidade lusófona e as fronteiras do império ${ }^{1}$
}

\author{
A history of others returns: the Lusophone Community and the borders of the empire \\ Gustavo Henrique Rückert \\ Universidade Federal dos Vales do Jequitinhonha e Mucuri - Diamantina - Minas Gerais - Brasil
} $\diamond$

\begin{abstract}
Resumo: Neste artigo, pretendemos analisar algumas marcas do hipercontemporâneo nas literaturas de língua portuguesa. Para isso, tomamos a ideia do contemporâneo enquanto as "trevas de nosso tempo", formulada por Giorgio Agamben. Nesse sentido, defendemos que as "trevas de nosso tempo" são os problemas relacionados às travessias identitárias das fronteiras da modernidade. Desse modo, analisaremos as obras Estive em Lisboa e lembrei de você, do brasileiro Luiz Ruffato, e $O$ meu nome é Legião, do português Lobo Antunes, as quais representam a questão do imigrante brasileiro e africano em Portugal. Como aporte teórico, utilizaremos conceitos de Homi Bhabha, Stuart Hall, Edward Saïd, João Guimarães Rosa, Boaventura de Sousa Santos e Margarida Calafate Ribeiro. Os resultados apontam que uma hipercontemporaneidade na comunidade lusófona está extremamente relacionada à questão colonial, uma vez que marcas identitárias (língua, nacionalidade, classe social, gênero, religiosidade) são impostas ou reivindicadas a partir das fronteiras que perduram do império.

Palavras-chave: Hipercontemporâneo; Imigração; Império
\end{abstract}

\begin{abstract}
In this article, we examine some traces of hyper-contemporary in Portuguesespeaking literatures. For this, we take the idea of contemporary as the "darkness of our time", formulated by Giorgio Agamben. In this regard, we argue that the "darkness of our time" are the problems related to identity crossings of the borders of modernity. Thus, we will analyze the works Estive em Lisboa e lembrei de você, by Brazilian Luiz Ruffato, and $O$ meu nome é Legião, by the Portuguese Lobo Antunes, which represent the question of Brazilian and African immigrants in Portugal. As a theoretical contribution, we will use concepts of Homi Bhabha, Stuart Hall, Edward Saïd, João Guimarães Rosa, Boaventura de Sousa Santos and Margarida Calafate Ribeiro. The results indicate that a hyper-contemporaryness in Lusophone community is extremely related to the colonial question, because identifying marks (language, nationality, social class, gender, religiousness) are imposed or claimed from the borders that remain of the empire.
\end{abstract}

Keywords: Hyper-contemporary; Immigration; Empire

Em sua proposta temática para o volume 51, número 4, a Revista Letras de Hoje instiga os pesquisadores a mapear os "sinais do hipercontemporâneo nas literaturas de língua portuguesa". No entanto, para melhor visualizarmos o presente, provocamos com a necessidade de olhar primeiro o passado. Explicamos: antes de levantar os sinais do que seria uma hipercontemporaneidade, é necessário delimitar o que se entende por ela. Nesse sentido, como já nos ensinou Proust, a

\footnotetext{
1 Este artigo é resultado parcial do projeto Transatlântico: diásporas, fronteiras e interidentidades nas literaturas de língua portuguesa, financiado pela CAPES por meio de uma bolsa PNPD e desenvolvido na Universidade Federal de Pelotas.
}

pretensa exatidão de qualquer recorte cronológico seria absurdamente imprecisa. E é evitando a simples demarcação cronológica que Giorgio Agamben formula uma das respostas mais produtivas para o assunto. Ao se perguntar o que é o contemporâneo, o teórico (AGAMBEN, 2009 , p. 60) entende que a contemporaneidade está na capacidade de escrever sobre "as trevas de seu tempo". Pensar então em sinais do hipercontemporâneo nessas literaturas, mais do que abordar as obras ainda quentes do prelo, seria adentrar as contradições políticas, econômicas, sociais e culturais em algum momento representadas em língua portuguesa e que impactam o nosso presente. 
Tomamos, portanto, como objetivo deste artigo pensar as trevas inscritas nas letras de hoje das literaturas de língua portuguesa. Os problemas de nosso tempo, diríamos, são oriundos das travessias das fronteiras identitárias impostas pela modernidade, sejam elas evidenciadas em questões de gênero, de classe, de religiosidade ou de nacionalidade. Refletir sobre o trânsito entre as demarcações de identidades culturais em língua portuguesa é então inevitavelmente pensar os limites do império, que, mesmo como ruína em um período pós- 25 de Abril, está lá presente, como fantasma a assombrar o horizonte da atualidade em língua portuguesa.

As fronteiras do império pelas quais transitam escritores como António Lobo Antunes, Lídia Jorge, Valter Hugo Mãe, Gonçalo Tavares, Isabel Figueiredo, Dulce Maria Cardoso, Luiz Ruffato, Ondjaki, José Eduardo Agualusa, Germano Almeida, entre tantos outros, são construções culturais erigidas em um longo processo, do qual são sintomas desde o mar como via de conquistas legitimadas pela religião em oposição à paciente espera amorosa da mulher nas cantigas de amigo até o mar como elemento representativo da grandiosidade de um império simbólico luso em Mensagem, de Fernando Pessoa (2006).

Nesse sentido, Os lusiadas configura um texto sempre presente, não por uma mítica atemporalidade, como alertou Eduardo Lourenço (1982), mas pela sua contemporaneidade na atribuição das fronteiras da língua portuguesa. "Eis aqui, quase cume da cabeça / De Europa toda, o Reino Lusitano, / Onde a terra se acaba e o mar começa," (CAMÕES, 2008, p. 84). Dessa forma, pensar o Oceano Atlântico como fronteira entre as identidades constituídas nos países de língua portuguesa é pensar uma fronteira tida como espaço do colonizador. A travessia é entendida assim como lusitana por direito. Ao se questionar sobre as culturas além das fronteiras atlânticas, o poema indaga: "Que gente será esta? (em si diziam)/ Que costumes, que Lei, que Rei teriam?" (CAMÕES, 2008, p.31). Na altura de Moçambique, quando as naus de Vasco da Gama se deparam com a alteridade ("Nem ele entende a nós, nem nós a ele" - CAMÕES, 2008, p. 152), os limites culturais são definidos. "Ele" não entende a nós pelo fato de sua cultura não ser dotada de uma língua com complexidade de raciocínio. Ignorada a diferença, o "nós" que se vê dotado de linguagem e complexidade impõe a violência do nome (Cf. SAID, 2007) ao outro, definindo-o "Selvagem mais que o bruto Polifemo" (CAMÕES, 2008, p. 15).

O diagnóstico da literatura portuguesa contemporânea como travessia pelos limites do império colonial é realizada com maestria por Margarida Calafate Ribeiro (2004; 2012) em suas, podemos dizer, histórias de regressos. Sua obra Uma história de regressos: império, guerra colonial e pós-colonialismo (2004) é marca fundamental nesse sentido ao analisar a literatura portuguesa do último quarto do século XX. A geração de Lobo Antunes, Lídia Jorge, Helder Macedo, Manuel Alegre, Wanda Ramos, João de Melo, entre outros, é lida como uma geração que representa a viagem de volta a Portugal, retornando da África ao velho centro de origem desse translatio imperii, em textos que configuram epitáfios da épica imagem lusa. Esses epitáfios geralmente são escritos a partir de escritores, narradores ou protagonistas que viveram os horrores das guerras coloniais e buscam trabalhar a tensão traumática entre escrita e memória.

Já em $O$ fim da história de regressos e o retorno a África: leituras da literatura contemporânea portuguesa (2012), a pesquisadora se volta para a literatura portuguesa do século XXI e vê na geração de Isabel Figueiredo, Dulce Maria Cardoso, Paulo Bandeira Faria, Rodrigo Guedes de Carvalho e António Teixeira Mota, entre outros, um novo interesse pela África. Assim, autores, narradores ou protagonistas que não viveram as guerras coloniais, mas são filhos de quem as viveu, têm suas pósmemórias atormentadas pelo familiar passado imperial que é herdado. A esse novo interesse pela relação com as antigas colônias, podemos incluir o recente Uma viagem à Índia, epopeia pós-moderna de Gonçalo Tavares que reverte a grandiosidade camoniana ao marcar a aventura de Bloom pela melancolia.

Ao dividir com profundidade de análise duas gerações literárias portuguesas em regressos à ex-metrópole primeiramente e à ex-colônia posteriormente, Calafate toma o português como ponto de referência da travessia pelas fronteiras do antigo império. De certa forma, sua análise trata de como a identidade de um país marcado por elementos como messianismo e expansionismo sofre rupturas em suas representações com o fim político do império. Nesse sentido, em um movimento histórico pendular, ora se aproximando ora se afastando, a África sempre surge como assombro à identidade democrática construída no pós-25 de Abril.

À análise de Calafate, propomos aqui acrescentar uma história de outros regressos. Obras como os romances O meu nome é Legião, do português Lobo Antunes, Estive em Lisboa e lembrei de você, do brasileiro Luiz Ruffato, Esse cabelo, da angolana Djaimilia Pereira de Almeida, ou a peça infanto-juvenil $O s$ vivos, o morto e o peixe frito, do angolano Ondjaki, problematizam outras trevas do nosso tempo: a busca dos ex-colonizados por melhores condições econômicas e sociais na antiga metrópole. Trata-se, portanto, de uma travessia que tem como protagonista o outro, aquele situado além do "mar português". Os outrora definidos "selvagem mais que o bruto Polifemo" avançam as fronteiras atlânticas, reivindicando sua cidadania no centro do império em ruínas. 
Para pensar as trevas do tempo de angolanos, moçambicanos, guineenses, são-tomenses, cabo-verdianos, brasileiros e timorenses que migram para Portugal, tomamos para fins de análise $O$ meu nome é Legião e Estive em Lisboa e lembrei de você, publicados respectivamente em 2007 e em 2009.

Na narrativa de Ruffato, Sergio de Souza Sampaio, o Serginho, tem seu depoimento transcrito por L.R. (as iniciais do próprio autor). A sua vida é contada em dois momentos: um primeiro na sua cidade natal, a pequena Cataguases, no interior do estado brasileiro de Minas Gerais; e um segundo em Lisboa, para onde migra quase que em fuga, em busca de sentidos para a sua vida a partir de uma reestruturação financeira. A divisão geográfica de seu relato é também existencial. A "parte brasileira" tem por título "como parei de fumar" e dá conta de uma vida de pobreza e de desajustes. Daí a vontade de mudança no cigarro e na geografia. A "parte portuguesa", que tem por título "como voltei a fumar", dá conta da desilusão de Serginho em Lisboa. A capital da antiga metrópole não se revela o sonho da prosperidade alimentado por Oliveira, português que vive em Cataguases. Daí a saudade da cidade natal e dos hábitos antigos, como o cigarro.

Já na obra de Lobo Antunes, o agente policial Gusmão, solitário e em fim de carreira, redige o inquérito policial (recheando-o de digressões existenciais) da investigação de uma série de crimes (entre eles assassinato, estupro e furto) cometidos por oito garotos entre 12 e 19 anos do Bairro $1^{\circ}$ de Maio, bairro afastado de Lisboa e habitado majoritariamente por imigrantes e descentes de imigrantes africanos. Assim, seja no discurso de Gusmão, dos demais agentes policiais, ou mesmo dos depoentes, fica explícito o ódio aos imigrantes, legitimando-se, inclusive, uma série de crimes (entre eles um assassinato e um incêndio) causados pela própria polícia.

Em ambos os textos (seja nos discurso de imigrantes, seja no discurso de portugueses), a situação de tensão criada no desajuste entre aquele que chega e os habitantes locais deixa claro que não há espaço para os que são oriundos das ex-colônias. A antiga metrópole continua a constituir fronteiras e fecha-se assim àqueles que configuram os excessos da história colonial e buscam refúgio no centro do sistema que os solapou.

De acordo com Stuart Hall (2006, p. 82), a segunda metade do século XX foi palco de um dos maiores movimentos de migração não planejada:

Impulsionadas pela pobreza, pela seca, pela fome, pelo subdesenvolvimento econômico e por colheitas fracassadas, pela guerra civil e pelos distúrbios políticos, pelo conflito regional e pelas mudanças arbitrárias de regimes políticos, pela dívida externa acumulada de seus governos para com os bancos ocidentais, as pessoas mais pobres do globo, em grande número, acabam por acreditar na "mensagem" do consumismo global e se mudam para os locais de onde vêm os "bens" e onde as chances de sobrevivência são maiores.

No início do século XXI, a situação não é diferente. De acordo com dados do Programa das Nações Unidas para o Desenvolvimento (PNUD, 2009), "aproximadamente 195 milhões de pessoas moram fora de seus países de origem, o equivalente a 3\% da população mundial, sendo que cerca de $60 \%$ desses imigrantes residem em países ricos e industrializados". Sabe-se, pelo agravamento dos conflitos no Oriente Médio e das condições sociais de muitos países africanos, que os números apresentados em 2009 pela ONU aumentaram exponencialmente em 2015. Uma legião de refugiados marcha em busca de melhores condições de vida em países desenvolvidos ou em desenvolvimento.

No caso de Portugal, com as guerras coloniais no século XX, além dos africanos, houve a volta massiva de portugueses que viviam (há algumas gerações) na África. Como resultado, o pequeno país ficou abarrotado de pessoas sem condições de emprego, de moradia, e, num sentido mais amplo, de dignidade e de cidadania. Os portugueses "retornados", como são definidos pelos portugueses que habitavam a antiga metrópole, são visto como "cafrealizados" (Cf SANTOS, 2010), refletindo-se o estigma imposto às culturas africanas ao longo de cinco séculos de colonização.

Dessa forma, apesar do fim político do império, com a independência das últimas colônias em 1975, suas fronteiras permanecem bastante sólidas no presente para o grande contingente de pessoas que abandonam as antigas colônias, sonhando com uma maior dignidade em suas vidas. No nível da linguagem, tão caro à constituição do império, as falas das personagens de Ruffato e de Lobo Antunes deixam claras essas fronteiras. $\mathrm{O}$ "Nem ele entende a nós, nem nós a ele" camoniano permanece mais atual que nunca.

A fala de Serginho, repleta de expressões da oralidade das classes média e baixa da região de Minas Gerais (até porque no plano ficcional o leitor está diante de um depoimento oral transcrito), torna-se repleta de estranhamento no momento em que narra sua vivência em Lisboa. O editor fictício opta pelos recursos do negrito e do itálico para registrar a pouca naturalidade com que o protagonista enuncia opções lexicais ou aspectos culturais das variantes europeias e africanas da língua portuguesa. Assim, o discurso de Serginho marca quase que um processo de aprendizado de uma língua estrangeira por si: 
Lisboa cheira sardinha no calor e castanha assada no frio, descobri isso revirando a cidade de cabeçapra-baixo, de metro, de eléctrico, de autocarro, de comboio, de a-pé, sozinho ou ladeado pela Sheila. Com ela de guia, visitamos um monte de sítios bestiais [...] (RUFFATO, 2009, p. 67).

$\mathrm{O}$ aspecto da diferença faz-se então perceptível pelo conflito, rompendo com a ideia totalitária da lusofonia. $\mathrm{O}$ teórico pós-colonial indiano Dipesh Chakrabarty (2015, p. 23) define a língua como um dialeto respaldado por um exército. Assim, a fala de Seginho traz em sua própria materialidade as marcas da imposição (bem como da resistência) de um "exército da língua portuguesa". Além da língua portuguesa, em seu emprego de garçom no Bairro Alto, o inglês surge também com estranhamento. $\mathrm{Na}$ tentativa de atender os turistas, a personagem demonstrava a tensão entre a fonética do português brasileiro e a da língua inglesa: "em dois tempos eu já encostava naqueles brancalhões e desatava o meu inglês, Rei ser, Rei mádam, Ria chípe fude, gude fude, uaine, fiche, mite, têm-quíu" (RUFFATO, 2009, p. 58).

A "estrangeiridade das línguas" (BHABHA, 2013), seja o inglês, mas principalmente o português, fica tão explícita que o alívio ao encontrar Rodolfo, outro brasileiro em Lisboa, é semelhante ao sentir-se em casa: “' 'Você é brasileiro?', confirmou, e, satisfeito, eu disse, 'Puxa vida, que bom encontrar alguém que fala a mesma língua da gente'", (RUFFATO, 2009, p. 46).

Se a língua constitui fronteira que perdura dos tempos coloniais e impede o imigrante de acessar o centro do império, ela (e seu exército), nas mãos dos falantes de visão colonial, torna-se o mais importante instrumento de xenofobia. Africanos e brasileiros seguem assim no século XXI como "selvagens mais que o bruto Polifemo": um outro incapaz de compreender e ser compreendido por estar além dos limites da cultura e da razão. Assim, racionalidade, ética e etnia são associadas na violência do nome imposta pelo discurso que perpassa a sociedade de uma forma ampla, e nas obras podem ser observadas em empreendedores, policiais, prostitutas, e até mesmo nos familiares de imigrantes e nos próprios imigrantes.

Em Estive em Lisboa, Serginho, que chegou a ser nominado "estúpido" por ser brasileiro, vê-se preterido de seu emprego diante da concorrência dos imigrantes ucranianos. A justificativa do empregador vai desde a esfera cultural até a racial:

\footnotetext{
"Nada contra vossa pessoa", desculpou, mas tinha contratado outro ucraniano, "Chegam cá" destemidos, formação superior, "Conhecem inglês, francês", mãode-obra mais qualificada pelo mesmo salário, "O Anatólio, por exemplo", graduado em agronomia, e eles querem realmente erigir uma vida nova, os brasileiros, sempre pensando em voltar, "Feitas as
}

contas" na ponta do lápis, mais sensato contratar um leste-europeu, e, além disso, "Não te ofendas, pá", os fregueses preferem ser atendidos por um gajo louro de olhos azuis, "Eu cá até discordo, os brasileiros", mais cordatos, mas o cliente é quem manda (...) (RUFFATO, 2009, p. 81)

O discurso do empreendedor chega a remontar os argumentos de Pero Vaz de Caminha, que, na sua carta ao Rei D. Manuel por ocasião do "achamento" do Brasil, depois de utilizar os termos "selvagem", "ingênuo" e "servil", recomenda, na conclusão do texto, que o rei português procure "salvar esta gente" (CAMINHA, 2013, p. 66). Salvá-los, no caso, adquiria a significação de livrar os índios dos próprios desconhecimento e primitividade, consequentemente aproveitando-se da sua dita servilidade. Como Serginho não foi "salvo da sua falta de cultura e ambição", não poderá ter sua servilidade (no caso marcada pela associação do adjetivo "cordatos" aos "brasileiros") explorada no estabelecimento. Afinal, o valor simbólico de um imigrante do leste europeu é superior, pois apesar de "imigrante" e "leste", é "europeu".

Em O meu nome é Legião, o mito lusotropicalista do bom colonizador, expresso acima, dá lugar ao discurso de ódio explícito, que perpassa inclusive a instituição policial e sua forma de agência. Na escrita do inquérito, Gusmão, ao descrever os jovens suspeitos como sendo um branco, um negro e seis mestiços, parte para a teorização racista típica da ciência do século XIX, vinculando raça ao que era entendido como comportamento patológico:

e todos os companheiros semi-africanos e num dos casos negro e portanto mais propensos à crueldade e violência gratuitas o que conduz o signatário a tomar a liberdade de questionarse preocupado à margem do presente relatório sobre a justeza da política de imigração nacional (ANTUNES, 2009, p. 10).

Se Gusmão lamenta pelo decadente presente português ("o que este país tem de sobra são mestiços e pretos" - ANTUNES, 2009, p.33) para questionar os líderes políticos pelo não fechamento das fronteiras aos imigrantes das antigas colônias, seu ajudante expressa o que, na sua opinião, deveria ser feito para garantir o estabelecimento daquilo que entende por ordem: "Ponham-me a mandar neste país durante cinco minutos e mato os pretos todos" (ANTUNES, 2009, p. 23).

Em atitude totalitária, herdeira da polícia fascista do Estado Novo, os agentes se incumbem de investigar, tomar conclusões e punir. Dessa forma, apesar de não serem governantes, impõem fronteiras aos imigrantes e de fato os chegam a matar, conforme o que esperam do estado. Os crimes cometidos pela instituição oficial são 
minimizados no discurso colonial que insiste em perdurar: "Os mestiços hão de enterrá-los descansem dado que os macacos se enterram uns aos outros, é da natureza dos bichos cavarem com as unhas sem entender porquê, esses instintos deles" (ANTUNES, 2009, p. 105).

A ideologia do discurso colonial, o qual representa os descentes africanos do século XXI ainda como selvagens e brutos, da mesma forma que eram representados cinco séculos atrás, acaba por influenciar na imagem que os próprios imigrantes fazem de si. A irmã de um dos suspeitos, que em seu depoimento trata de anunciar-se como trabalhadora e mãe de família, e não prostituta, como entende que se espera das pessoas em sua condição social, questiona-se: "teremos alma nós pretos?" (ANTUNES, 2009, p.167). Em Os condenados da terra, Frantz Fanon (1968), ao analisar os problemas psicológicos dos argelinos, havia percebido que estes têm a ver com a estrutura social que o sistema colonial francês impôs. Assim, o colonizado acaba por ver-se reduzido à própria representação imposta pelo colonizador.

Outro aspecto fundamental no que tange às relações sociais herdadas do colonialismo e está fortemente arraigada à imagem que a personagem descendente de imigrantes tem de si está na relação de gênero. Para Boaventura de Sousa Santos (2009), o colonialismo português, que nos primeiros séculos não contou com a presença institucional e militar nas colônias, acabou por fazer com que os portugueses degradados ou aventureiros precisassem inserir-se nas sociedades locais para explorá-las. Daí o signo da violência sexual representada no conceito de "mestiçagem", que remonta à união imposta pelo colonizador branco às índias e às africanas.

Em Estive em Lisboa, as brasileiras são frequentemente associadas ao signo "rameiras". Sheila, que se prostituía em Lisboa sonhando regressar ao Brasil com melhores condições econômicas, por quem Serginho nutria esperanças afetivas, era tida como uma índia da carta de Caminha ou uma das ninfas das Ilhas dos Amores. Ou seja, alguém que em sua condição de ingenuidade e de servilidade está à disposição do homem europeu. No entanto, como as mulheres descritas séculos atrás pelos viajantes, ela devia respeitar as fronteiras e manter-se afastada da civilização ocidental em sua ilha paradisíada tropical: "parecia que estava escrito na testa Prostituta, onde entrava tratavam ela mal, aos chutos e pontapés, como se portasse sida, ou lepra, e então, conformada, recolhia no seu canto" (RUFFATO, 2009, p. 67).

Em $O$ meu nome é Legião, um homem branco, padrasto de um dos suspeitos, aproxima sua mulher, bem como os demais habitantes do bairro, à condição de animais em seu discurso, inclusive no que diz respeito à sexualidade: o miúdo mestiço, a minha esposa mestiça, os primos mestiços em cada canto do Bairro (acasalam entre si como os bichos) sumidos em gretas, furnas (exactamente como bichos) ou depenando noitibós na rua (até escaravelhos comiam garanto) (ANTUNES, 2009, p. 112-113)

Dessa forma, representados ou sob a condição de bons selvagens, em sua ingenuidade servil à disposição do europeu, ou sob a condição de selvagens ameaçadores, dados ao vício e ao crime, os imigrantes de Lobo Antunes e de Ruffato acabam por viver em uma Lisboa paralela. Do lado de cá da fronteira, a periferia, o submundo das drogas, da prostituição, da ausência de leis inclusive na agência policial; do lado de lá o Portugal europeu, aberto não a imigrantes mas a turistas e a mercadorias.

Serginho, antes de conhecer Sheila, sequer conhecia os famosos pontos turísticos da capital portuguesa. Vivia em outra Lisboa, a Lisboa das pensões baratas, do trabalho abusivo e ilegal, dos empréstimos clandestinos. Por influência de Sheila, envolve-se em uma negociação com um agiota angolano. O homem, ex-combatente da FNLA, havia fugido do seu país após a derrota para o MPLA. Dizia que, "embora cidadão da Comunidade Europeia, 'Sinto-me exilado', angolano de corpo e alma, apenas comia calulu, moamba de galinha com funge, muzungué com farinha de pau, muito óleo de palma e jindungo" (RUFFATO, 2009, p. 75). Vivendo sua cultura à distância, dizia que "Se calhar, estamos todos na mesma situação, meus queridos" (RUFFATO, 2009, p. 75). Ao se colocar no mesmo drama de exilados, no entanto, o agiota mostra que o auxílio que presta aos ditos colegas brasileiros, angolanos, guineenses, moçambicanos, cabo-verdianos e são-tomenses é na verdade a violenta exploração em busca do lucro no sistema de capitalismo globalizado. Como garantia do empréstimo ilegal concedido à Sheila, confiscou os passaportes de Serginho e de sua companheira.

Já o agente Gusmão, ao descrever o bairro dos suspeitos, o descreve da seguinte forma:

Bairro $1^{\underline{O}}$ de Maio situado na região noroeste da capital e conhecido pela sua degradação física e inerentes problemas raciais isto é um pudim de edifícios de matérias não nobres, fragmentos de andaimes, restos de alumínios, canas e habitado por gentes de Angola, criaturas mestiças ou negras [...] (ANTUNES, 2009, p. 24).

[...] onde vendiam ouro, electrodomésticos e droga e onde de vez em quando um cadáver a que ninguém atendia salvo para lhe despir uma peça até o abandonarem nu [...] (ANTUNES, 2009, p. 30). 
Assim, o centro do império que colonizou brasileiros e africanos torna-se inacessível para esses sujeitos. Se foi exatamente a exploração e a espoliação das gentes de Áfricas e de Brasis que sustentou a imagem de Portugal como império, agora é negado ao colonizado a participação nesse mesmo império. Tendo a condição de cidadania plena na comunidade lusófona negada, os imigrantes acabam por formar guetos que constituem verdadeiras margens no próprio centro.

Entende-se, dessa forma, a relação irônica do título da obra de Ruffato. O emblema capitalista do mercado turístico é adotado em sentido inverso. Serginho não foi a Lisboa a passeio, não desfrutou de momentos felizes e não voltou com pequenos regalos aos seus amigos e familiares. Foi recebido a "chutos e pontapés", como o nome da banda de rock utilizada em uma das epígrafes da obra. Epígrafe, aliás, que joga com o título: "Sem me lembrar/ de ti eu vivo/ Em Lisboa/A Magnífica". Serginho parte em Lisboa para esquecer da vida medíocre que sua condição social o impôs no interior do Brasil. Mas, sem lugar na imaginada Lisboa Magnífica, não consegue esquecer a vida humilde em Cataguases. Pelo contrário, o sofrimento vivido em Portugal o faz lembrar constante e saudosamente do Brasil. No entanto, vale salientar, tratase também de um "Brasil Magnífico", imaginário, no qual seria bem-sucedido empreendedor imobiliário após o regresso de Lisboa.

Título e epígrafe também se relacionam no romance de Lobo Antunes. Antecedendo o inquérito de Gusmão, há uma passagem do evangelho bíblico de Lucas abrindo o livro. Trata-se de "um homem da cidade, possesso de vários demônios, que desde há muito não se vestia nem vivia em casa mas nos túmulos". Ao ser exorcizado por Jesus, ele responde: "O meu nome é Legião". Tal qual os demônios, que são muitos, os imigrantes vivem marginalizados em um Portugal que os deseja exorcizar... Nas páginas redigidas por Gusmão, são demônios que passam a tomar conta de sua escrita, seja pelo expresso medo que o policial tem dos descendentes africanos, seja pela confusão mental que faz, confundindo-os com sua própria filha, seja nas vozes que por meio dos depoentes do Bairro 1ำ de Maio vão entrando no jogo polifônico do romance.

Os imigrantes de Ruffato e de Lobo Antunes tornam-se então exilados. Sua condição econômica não os permite o regresso. Assim, não encontram em Portugal a almejada independência econômica e sua consequente dignidade social, mas também não possuem mais o amparo do sentimento de pertença e integração em seus países de origem, marcados também pela miséria da espoliação colonial e agora somente um dado da memória que tanto os atormenta.
Lançar-se ao Oceano Atlântico, fronteira do império, torna-se assim travessia ${ }^{2}$ : ou seja, um lança-se às incertezas de uma terceira margem. O poema de Miguel Torga na segunda epígrafe de Estive em Lisboa é bastante significativo da angústia que causa a incompletude da travessia. Desabafa o eu-lírico, "ah, desterro do rosto em cada face, / Tristeza dum regaço repartido! / Antes o desespero naufragasse / Entre o chão encontrado e o chão perdido". As personagens de Ruffato e Lobo Antunes também se lançaram à travessia e passam a viver o "entrelugar" (BHABHA, 2013) de uma terceira margem do Atlântico.

Esse vagar que não tem volta desestabiliza as bases identitárias construídas na modernidade europeia. $\mathrm{O}$ ser brasileiro, angolano, português, falante do português, membro da comunidade lusófona, homem, mulher, vacilam então entre o chão encontrado das fronteiras persistentes do antigo império e o chão perdido da ilusão comunitária.

A posição de conflito dessas personagens entre um Portugal que não os acolhe e os seus países de origem, agora presentes apenas na memória, leva então à extrema angústia existencial. Assim, Rodolfo desabafa: "Nós estamos lascados, Serginho’, aqui em Portugal não somos nada, 'Nem nome temos', somos os brasileiros, 'E o que a gente é no Brasil?', nada também, somos os outros" (RUFFATO, 2009, p. 78). Serginho, ao observar a condição dos demais imigrantes, constata o desespero causado pela travessia nas fronteiras do império:

ficava olhando praqueles pobres-diabos, africanos, árabes, indianos, babel de raças e cores, se espremerem dois-três na mesma cabina de telefone, esgoelando, chorando, uma vez, perto do Natal, uma senhora negra, baixa e gorda, enfiada numa roupa estampada, cabelos começando a alvejar, desmaiou no decorrer de uma ligação, socorremos ela, apareceu uma cadeira, um copo dágua, um abano, quando voltou a si, socando os pés no chão, a jabuticaba dos olhos clamou seu desespero num português estropiado que ninguém entendia mas que todos adivinhamos, o desalento imigrante de quem sabe que de nada serve essa vida se a gente não pode nem mesmo aspirar ser enterrado no lugar próprio onde nasceu (RUFFATO, 2009, p. 73).

Se a primeira geração de imigrantes sofre pela impossibilidade de voltar a integrar-se plenamente ao seu local e culturas de origem, elemento muito presente nas culturas africanas e afro-brasileira, a geração de descendentes de imigrantes, a qual já nasceu em Portugal,

\footnotetext{
2 Adaptamos a termo a partir da obra do escritor brasileiro Guimarães Rosa. Em seu conto "A terceira margem do rio" (ROSA, 1994), a personagem que se lança ao rio não encontra sua margem oposta, tampouco a de origem, e sua travessia permanece sempre incompleta. A terceira margem do rio constitui então o mistério do imprevisível, ao passo que a travessia torna-se devir.
} 
sofre o não integrar-se à sociedade lusitana e gozar dos mesmos direitos. Em $O$ meu nome é Legião, a mãe de um dos suspeitos lamenta: "- Porque não sou branca eu? - Porque não somos brancos todos? - Porque não moramos em Lisboa porque nos tratam mal porque não temos dinheiro?" (ANTUNES, 2009, p. 152).

Dessa forma, diante do desalento imigrante, que não se sente pertencente à parte alguma, as personagens de ambos romances buscam, à sua maneira, integrar-se ou fazer-se notar. Serginho desabafa: "E foi assim que, depois de seis anos e meio, pouco mais ou menos, entrei numa tabacaria, pedi um maço de SG, um isqueiro, tirei um cigarro, acendi e voltei a fumar" (RUFFATO, 2009, p. 83). Por mais que o ato de fumar possa representar um desintegrar-se em fumaça, também pode representar um desintegrar-se para impregnar-se mesmo que, indesejado, na antiga metrópole. E integrar-se a Lisboa é para Serginho integrar-se a uma Cataguases que também nunca teve: a Cataguases da estabilidade financeira e do prestígio social.

Em O meu nome é Legião, diante do profundo abismo social que é exposto, a violência surge como único ponto de contato entre as duas distintas realidades evidenciadas pelas fronteiras do antigo império. Assim, as agressões são um grito de desespero em meio à solidão vivenciada no século XXI. No caso dos meninos, a agressão é a única forma de fazerem-se notar pela sociedade lisboeta, que por sua vez tem a agressão como forma de controle do medo que sente pela diferença. O diálogo que os meninos mantêm com uma de suas vítimas durante episódio de agressão revela exatamente esse apelo de existência/ inexistência expresso pela violência. De um lado, a indiferença pela condição do imigrante. Do outro, o desespero por fazer-se notar enquanto sujeito:

\section{- O que desejam os senhores?}

não pelos lábios, pela maçã de adão visto que a apertar o guiador de lábios selados, escancararam-se no momento em que a mira de uma pistola do Exército lhe rasgou a bochecha e a quantidade de dentes meus irmãos que o pavor traz consigo, caninos, prémolares, molares e uma porção deles sem nome que ignorávamos existirem, o pinoca quis tirar o lenço da algibeira mas filaram-lhe o cotovelo

- Não somos senhores somos pretos (ANTUNES, 2009, p. 17)

Retomando, por fim, as reflexões iniciais propostas neste artigo, concluímos que a hipercontemporaneidade em língua portuguesa inicia na colonização. Pensar o presente no qual se defende, por diversos motivos, uma comunidade lusófona, é pensar cinco séculos de império. Assim, os sinais de uma hipercontemporaneidade nas literaturas de língua portuguesa atravessam a cronologia e dialogam com uma tradição secular para mostrar que as trevas de nosso tempo continuam construindo "brutos Polifemos" no interior do imaginário linguístico.

Analisar a representação dessa alteridade por escritores como Ruffato e Lobo Antunes faz-se extremamente necessário, pois revela uma história de regressos indesejados, os regressos daqueles que formam o excesso da colonização. O escritor brasileiro, na Feira do Livro de Frankfurt, em 2013, ao analisar a questão da globalização, afirmou: "as fronteiras caíram para as mercadorias, não para o trânsito das pessoas". ${ }^{3}$ Diante da análise que expusemos, a comunidade lusófona mostra-se também uma comunidade de fronteiras relativas. Sua relatividade é política e remonta ao império. A travessia de pessoas que geram lucro encontra fronteiras líquidas, pois garante a continuidade da colonialidade em tempos de neoliberalismo. Já a travessia daqueles que cobram uma dívida de cinco séculos esbarra em fronteiras um tanto quanto antigas. Apesar de envelhecidas, porém, nos parece que são ainda bastante sólidas e que nos serão contemporâneas por muito tempo.

\section{Referências}

AGAMBEN, Giorgio. O que é contemporâneo? E outros ensaios. Trad. Vinícius Nikastro Honesko. Chapecó: Argos, 2009 .

ANTUNES, António Lobo. O meu nome é Legião. Rio de Janeiro: Objetiva, 2009.

BHABHA, Homi. O local da cultura. Trad. Myriam Ávila, Eliana Lourenço Reis e Gláucia Gonçalves. Belo Horizonte: Editora UFMG, 2013.

CAMINHA, Pero Vaz de. Carta de achamento do Brasil. In: CASTRO, Silvio. A carta de Pero Vaz de Caminha. Porto Alegre: L\&PM, 2013. p. 43-67.

CAMÕES, Luís de. Os Lusíadas. Porto Alegre: L\&PM, 2008.

CHAKRABARTY, Dipesh. A poscolonialidade e o artificio da história. Trad. Erahsto Felício. Disponível em: <https:// pt.scribd.com/doc/71612645/CHAKRABARTY-Dipesh-Aposcolonialidade-e-o-artificio-da-historia>. Acesso em: 15 fev. 2015 .

FANON, Frantz. Os condenados da terra. Rio de Janeiro: Civilização Brasileira, 1968.

FOUCAULT, Michel. As palavras e as coisas: uma arqueologia das ciências humanas. Trad. Salma Tannus Muchail. São Paulo: Martins Fontes, 2000.

HALL, Stuart. A identidade cultural na pós-modernidade. Trad. Tomaz Tadeu da Silva e Guacira Lopes Louro. Rio de Janeiro: DP\&A, 2006.

\footnotetext{
Disponível em: <http://cultura.estadao.com.br/noticias/geral,leia-aintegra-do-discurso-de-luiz-ruffato-na-abertura-da-feira-do-livro-defrankfurt,1083463>. Acesso em: 20 dez. 2015
} 
LOURENÇO, Eduardo. Camões no presente. In: . $O$ labirinto da saudade: psicanálise mítica do destino português. Lisboa: Dom Quixote, 1982.

PESSOA, Fernando. Mensagem. Porto Alegre: L\&PM, 2006.

PNDU. Relatório de desenvolvimento humano 2009. Disponível em: <http://www.pnud.org.br/hdr/arquivos/RDHglobais/ hdr2009-portuguese.pdf>. Acesso em: 22 dez. 2015.

RIBEIRO, Margarida Calafate. O fim da história de regressos e o retorno a África: leituras da literatura contemporânea portuguesa. In: BRUGIONI, Elena et al. (Orgs.). Itinerâncias: percursos e representações da pós-colonialidade. Porto: Edições Húmus, 2012. p. 89-100.

RIBEIRO, Margarida Calafate. Uma história de regressos: império, guerra colonial e pós-colonialismo. Porto: Edições Afrontamento, 2004.

ROSA, João Guimarães. A terceira margem do rio. In: Ficção completa. Rio de Janeiro: Nova Aguilar, 1994. Vol. 2. p. 409-413.
RUFFATO, Luiz. Estive em Lisboa e lembrei de você. São Paulo: Companhia das Letras, 2009.

SAID, Edward. Orientalismo: o Oriente como invenção do Ocidente. Trad. Rosaura Eichenberg. São Paulo: Companhia das Letras, 2007.

SANTOS, Boaventura de Sousa. Entre Próspero e Caliban: colonialismo, pós-colonialismo e interidentidade. In: gramática do tempo: para uma nova cultura política. São Paulo: Cortez, 2010. Vol. 4, p. 227-276.

SANTOS, Boaventura de Sousa. Portugal: tales of being and not being. Portuguese Literary \& Cultural Studies. University of Massachusetts Dartmouth, 2009. Disponível em: <http://www. plcs.umassd.edu/docs/sousasantos 090414.pdf>. Acesso em: 10 jul. 2012.

Recebido: 13 de abril de 2016.

Aprovado: 02 de julho de 2016

Contato: gh.ruckert@gmail.com 